\title{
Outbreak of haemolytic uraemic syndrome and bloody diarrhoea due to Escherichia coli O104:H4, south-west France, June 2011
}

G Gault ${ }^{1}$, F X Weill ${ }^{2}$, P Mariani-Kurkdjian³ ${ }^{3}$ N Jourdan-da Silva ${ }^{4}$, L King ${ }^{4}$, B Aldabe ${ }^{1}$, M Charron ${ }^{1}$, N Ong ${ }^{1}$, C Castor ${ }^{1}$, M Macé $^{2}$, E Bingen 3 ,

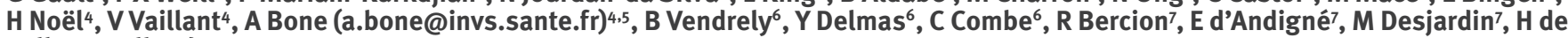
Valk $^{4}$, P Rolland ${ }^{1}$

1. Cellule interrégionale d'épidémiologie (CIRE) Aquitaine, France

2. Institut Pasteur, Centre National de Référence des Escherichia coli et Shigella, Paris, France

3. Laboratoire associé au CNR des Escherichia coli et Shigella, Service de Microbiologie, Hôpital Robert Debré, Paris, France

4. French Institute for Public Health Surveillance (Institut de Veille Sanitaire, InVS), St Maurice, France

5. European Programme for Intervention Epidemiology (EPIET), European Centre of Disease Prevention and Control (ECDC), Stockholm, Sweden

6. Centre Hospitalier Universitaire de Bordeaux, Bordeaux, France

7. Hôpital des Instruction des Armées Robert Piqué, Villenave-D’ornon, France

Citation style for this article:

Gault G, Weill FX, Mariani-Kurkdjian, Jourdan-da Silva N, King L, Aldabe B, Charron M, Ong N, Castor C, Macé M, Bingen E, Noël H, Vaillant V, Bone A, Vendrely B, Delmas Y, Combe C, Bercion R, d'Andigné E, Desjardin M, de Valk H, Rolland P. Outbreak of haemolytic uraemic syndrome and bloody diarrhoea due to Escherichia coli O104:H4, south-west France, June 2011 .

Euro Surveill. 2011;16(26):pii=19905. Available online: http://www.eurosurveillance.org/ViewArticle.aspx?Articleld=19905

Article published on 30 June 2011

As of 12:00 28 June 2011,15 cases of haemolytic uraemic syndrome (HUS) or bloody diarrhoea have been identified in the Gironde, south-west France. Investigations suggest the vehicle of transmission was sprouts, served at an event in Bègles on 8 June 2011. A strain of shiga toxin- producing Escherichia coli $0104: \mathrm{H}_{4}$ has been isolated from five cases. This strain is genetically related to the strain identified in the recent $E$. coli $\mathrm{O}_{104}: \mathrm{H}_{4}$ outbreak in Germany, and shares the same virulence and antimicrobial resistance characteristics.

\section{Outbreak description}

On 22 June 2011, the Cellule interrégionale d'épidémiologie (CIRE) Aquitaine, the regional office of the French Institute for Public Health Surveillance, was notified by the Robert Picqué Hospital in Bordeaux, south-west France, of eight cases of haemolytic uraemic syndrome (HUS) or bloody diarrhoea. Six of the cases lived in close proximity to one another in the commune of Bègles, in Bordeaux. Of these six cases, four were women (aged 41-78 years) and two were men (aged 34-41 years). Dates of symptom onset were between 15 and 20 June.

A case of HUS was defined as a person with acute renal failure and either microangiopathic haemolytic anaemia and/or thrombocytopenia. A possible outbreak case was defined as a case of HUS or a case of bloody diarrhoea without an alternative diagnosis in the French department (administrative region) of Gironde with a date of symptom onset since 10 June 2011. Active case finding has been carried out through contact with emergency, nephrology and intensive care departments of local hospitals, and general practitioners and out-of-hours doctors, and through the existing paediatric HUS surveillance network. Enhanced surveillance for cases of HUS or bloody diarrhoea in the rest of France has been implemented.

As of 12:00 28 June 2011, a further seven cases have been identified and investigated, bringing the total number of cases investigated to date to 15 cases of bloody diarrhoea, eight of whom have developed HUS.

\section{Epidemiological investigations}

The initial eight cases were interviewed using a standardised semi-structured questionnaire exploring food consumption, travel history and contact with other people with diarrhoea in the seven days before symptom onset. Initially no common food, visits to markets, restaurants or events, animal contact or leisure activity was identified. None of the cases reported eating sprouts. Only three of the cases shared the same municipal tap-water network. One of the cases had travelled away from home in France during the seven days before symptom onset and none had travelled abroad.

Given that a common exposure had not been identified, the predominance of adult women among the cases and the recent experience of the German sprout-related Escherichia coli 0104: $\mathrm{H}_{4}$ outbreak in Germany [1,2], a second questionnaire was developed that included an in-depth exploration of vegetable consumption in the two weeks before illness.

Further questioning of the initial eight cases and seven newly identified cases indicated that 11 of these 15 cases had attended an open day at a children's 
community centre on 8 June, at which a cold buffet was served consisting of crudités (raw vegetables), three dips, industrially produced gazpacho, a choice of two cold soups (carrot and cumin, and courgette), pasteurised fruit juices and individual dishes composed of white grapes, tomatoes, sesame seeds, chives, industrially produced soft cheese and fresh fruit. The soups were served with fenugreek sprouts, a small amount of which were also placed on the crudite dishes. Mustard and rocket sprouts, still growing on cotton wool, were used to decorate the crudite dishes. One of the 11 cases has not yet been fully questioned because of a deteriorating clinical condition, but is known to collect their grandchildren from the centre and may have attended the event. The remaining four cases had no obvious links to the centre.

Among the 11 cases with links to the centre, nine reported consuming sprouts at the event on 8 June; two cannot yet be fully questioned. Of these 11 cases, eight have HUS and three bloody diarrhoea. Seven are women aged 31-64 years and four are men aged 34-41 years. Dates of symptom onset are between 15 and 20 June (Figure). For the eight cases with a well-defined date of symptom onset, the incubation period ranges from 7 to 12 days (median: 9 days).

\section{Microbiological investigations}

A strain of $E$. coli $0104: \mathrm{H}_{4}$ possessing the stx2 gene, encoding Shiga toxin, has been isolated from five HUS cases, all of whom consumed sprouts at the event at the children's community centre. The strain is negative for the genes coding for intimin (eae), haemolysin A ( $h l y A)$ and EAST1 toxin (astA) and positive for the $a g g R$ gene which regulates the expression of aggregative adherence fimbriae. The antimicrobial resistance pattern of the strain is similar to that seen in the outbreak strain in recent $E$. coli O104: $\mathrm{H}_{4}$ outbreak in Germany [3](ampicillin resistant $(R)$, cefotaxime $R$, ceftazidime $R$, imipenem sensitive (S), streptomycin $R$, kanamycin $S$, gentamicin $S$,

\section{FIGURE}

Cases of HUS or bloody diarrhoea due to enterohaemorrhagic Escherichia coli O104:H4 with date of symptom onset since 10 June 2011, Gironde, France, June 2011 ( $n=14$ )

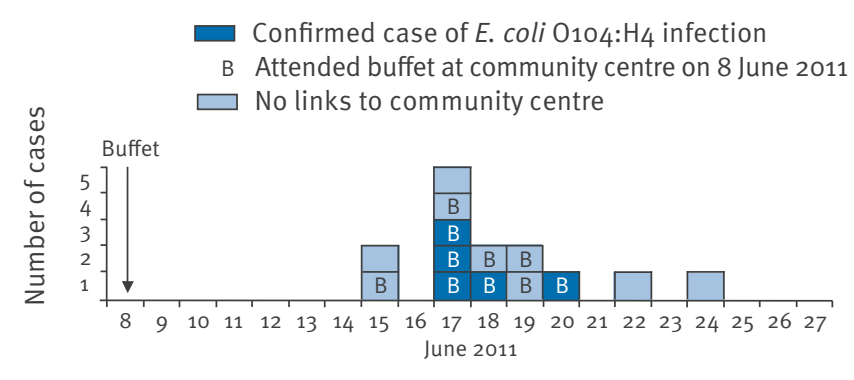

Date of symptom onset

HUS: haemolytic uraemic syndrome.

Of the 15 cases of HUS or bloody diarrhoea, date of symptom onset was unavailable for one case, who attended the buffet on 8 June 2011. sulfamethoxazole $R$, trimethoprim $R$, cotrimoxazole $R$, tetracycline $R$, chloramphenicol $S$, nalidixic acid $R$ and ciprofloxacin S). Our PCR analysis indicates the presence of the extended-spectrum beta-lactamase (ESBL) bla ${ }_{\mathrm{CTX}-\mathrm{M}-15}$ (group 1) gene and the penicillinase bla TEM gene.

Strains of $E$. coli $0104: \mathrm{H}_{4}$ isolated from two imported cases in France linked to the E. coli $\mathrm{O}_{104}: \mathrm{H}_{4}$ outbreak in Germany in May and June 2011 were compared by two molecular techniques (Rep-PCR $[4,5]$ and pulsedfield gel electrophoresis (PFGE), using a standardised PFGE using either Xbal or Notl [6]) with strains of $E$. coli 0104: $\mathrm{H}_{4}$ isolated from three patients in the Bordeaux outbreak. The results of these analyses show the genetic relatedness of the outbreak strains in France and Germany. The profile of the outbreak strains in the two countries differs from the profiles of two $E$. coli 0104: $\mathrm{H}_{4}$ stx2 strains isolated in 2004 and 2009 and from two other strains of serotypes E. coli $\mathrm{O}_{104}: \mathrm{H}_{21}$ and $0104: \mathrm{H}_{12}$. Comparison by whole-genome sequencing and optical maps will be performed in the coming days.

\section{Food trace-back investigations}

Food trace-back investigations were initiated on 24 June. The sprouts served at the event on 8 June had been grown from rocket, mustard and fenugreek seeds planted at the centre during 2 to 5 June. The fenugreek seeds were first soaked in tap water for 24 hours then placed in a jam jar topped with gauze and then rinsed with tap water two or three times a day. The mustard and rocket seeds were germinated on cotton wool moistened with tap water. They were harvested on 8 June to be served at the buffet. The seeds were purchased from a branch of a national chain of gardening retailers, having been supplied by a distributor in the United Kingdom. Leftover mustard and rocket seeds, gazpacho and tap water samples from the community centre have been sent for microbiological analysis, as have samples of rocket, mustard, fenugreek and other seeds from the French gardening retailer. Preliminary results are currently being analysed.

\section{Control measures}

Consumers have been advised by the French authorities not to eat raw sprouts, to thoroughly clean utensils used for germination and cooking, and to wash their hands thoroughly after contact with seeds and sprouts. Colleagues in other European countries were informed of this outbreak on 24 June via the Epidemic Intelligence Information System (EPIS) and Early Warning Response System (EWRS) of the European Centre of Disease Prevention and Control (ECDC). A European Food Standards Agency (EFSA) and ECDC joint rapid risk assessment has been carried out [7]. This assessment strongly recommends that consumers do not grow sprouts for their own consumption and do not eat sprouts or sprouted seeds unless thoroughly cooked. 


\section{Conclusions}

Preliminary data indicate that this outbreak shares the same novel epidemiological, clinical and microbiological features identified in the $E$. coli $0104: \mathrm{H}_{4}$ outbreak in Germany [8], including a predominance of adult women among the cases, an unusually high proportion of HUS cases among identified possible outbreak cases, a longer median incubation period than expected for cases of Shiga toxin-producing $E$. coli infection, and a genetically related $E$. coli $0_{104}: \mathrm{H}_{4}$ producing a CTX-M ESBL. The two outbreaks may share the same vehicle of transmission. A cohort study of those attending the event at the community centre and further epidemiological, microbiological and food trace-back investigations are underway. The possibility of similar outbreaks in France or elsewhere in Europe cannot be excluded.

\section{Acknowledgments}

Special thanks to the Agence Régional de la Santé Aquitaine, Bégles town council, Alexandra Mailles, Véronique Goulet, Gilles Delmas, Elisabeth Couturier, Christine Saura, Didier Gruson, Bruno Souillé, Isabelle Carles, Monique Lejay-Collin, Corinne Ruckly and Charlotte Balière for their assistance in the investigation of this outbreak.

\section{References}

1. Frank C, Faber MS, Askar M, Bernard H, Fruth A, Gilsdorf $A$, et al. Large and ongoing outbreak of haemolytic uraemic syndrome, Germany, May 2011. Euro Surveill. 2011;16(21): pii=19878. Available online: http://www. eurosurveillance.org/ViewArticle.aspx?Articleld $=19878$

2. Frank C, Werber D, Cramer JP, Askar M, Faber M, an der Heiden $M$, et al. Epidemic profile of Shiga-toxin-producing Escherichia coli $\mathrm{O}_{104: \mathrm{H}} 4$ outbreak in Germany - preliminary report. N Engl J Med. 2011 Jun 22. [Epub ahead of print].

3. Bielaszewska M, Mellmann A, Zhang W, Köck R, Fruth A, Bauwens A, et al. Characterisation of the Escherichia coli strain associated with an outbreak of haemolytic uraemic syndrome in Germany, 2011: a microbiological study. Lancet Infect Dis. 2011 Jun 22. [Epub ahead of print].

4. Bonacorsi S, Bidet P, Mahjoub F, Mariani-Kurkdjian P, AitIfrane S, Courroux C, et al. Semi-automated rep-PCR for rapid differentiation of major clonal groups of Escherichia coli meningitis strains. Int J Med Microbiol. 2009,299(6):402-9.

5. Boumghar-Bourtchai L, Mariani-Kurkdjian P, Bingen E, Filliol I, Dhalluin A, Ifrane SA, et al. Macrolide-resistant Shigella sonnei. Emerg Infect Dis. 2008;14(8):1297-9.

6. Ribot EM, Fair MA, Gautom R, Cameron DN, Hunter SB, Swaminathan B, et al. Standardization of pulsed-field gel electrophoresis protocols for the subtyping of Escherichia coli 0157:H7, Salmonella, and Shigella for PulseNet. Foodborne Pathog Dis. 2006;3(1):59-67.

7. European Food Safety Authority (EFSA)/European Centre for Disease Prevention and Control (ECDC). EFSA/ECDC joint rapid risk assessment. Cluster of haemolytic uremic syndrome (HUS) in Bordeaux, France. 29 June 2011 (updated from 24 June). Stockholm: ECDC; 2011. Available from: http://ecdc.europa.eu/ en/publications/Publications/2011June29 RA_JOINT_EFSA STEC_France.pdf

8. Jansen A, Kielstein JT. The new face of enterohaemorrhagic Escherichia coli infections. Euro Surveill. 2011;16(25):pii=19898. Available from: http://www. eurosurveillance.org/ViewArticle.aspx?Articleld $=19898$ 